\title{
How Tanzanian Universities Can Respond to Increasing Market Demands of Specialized Forms of English Language Learning and Communication Skills
}

\author{
Hashim I. Mohammed ${ }^{1} \&$ Onesmo S. Nyinondi, ${ }^{1, *}$ \\ ${ }^{1}$ Department of Language Studies, College of Social Sciences and Humanities, Sokoine University of Agriculture, \\ Tanzania \\ *Correspondence: Department of Language Studies, Campus College of Social Sciences and Humanities, Sokoine \\ university of Agriculture, Tanzania. Tel: 255-752-445-434. E-mail: onesmon@hotmail.com
}

Received: March 6, 2016 Accepted: March 16, 2016 Online Published: April 27, 2016

doi:10.5430/wjel.v6n2p1 URL: http://dx.doi.org/10.5430/wjel.v6n2p1

\begin{abstract}
English language and communications skills have undergo tremendous changes in the recent years globally. Increasingly, people realise that they need English language and communication skills not only in employment but also in full participation in social and political discourses, and Information and Communication Technology. Studies have shown that while learners have the motivation and innate ability to learn English, there is lack of requisite opportunities to learn and practice the language. This is because many English language learning proficiency programmes especially in Tanzania are unstructured and not tailored to learners' particular interests; this is in addition to using methodologies that emphasize on teaching about language instead of teaching language use. The current study therefore sought to explore the roles in which universities in Tanzania could play to address the rising market demand of English language proficiency programmes with the aim of providing outreach services and generate revenue. Face to face interviews, telephone conversations, focus group discussion, questionnaires, and documentary review were carried out during data collection. The findings show that the demand for English language proficiency programmes in Tanzania is strong. Similarly, the assessment of motivation and expectation indicates that availability of professional teachers and practical sessions, fair fee structure, and learners' passion for learning the language were key drivers behind attending the programme. This implies that English language proficiency is a potential niche market which Tanzanian universities could exploit to meet the rising language demands and at the same time generate the much required income.
\end{abstract}

Keywords: English language proficiency; communications skills; universities; market demand; English specialised forms; language learning

\section{Introduction and Problem Statement}

The profile of English language and communications skills has generally been undergoing tremendous changes in the recent years particularly in Africa. Many countries even those which were not originally English speaking or where English is not commonly used for wider communication for example Algeria, Angola, Ethiopia, Morocco, Mozambique, Rwanda, Senegal, Tunisia, Rwanda, and Burundi are striving to adopt English as one of the official languages in their communication milieu (Adkins, 2014). For example, Rwanda adopted English as the official language of instruction in the schools in late 2008. As per government statement, "greater part of the school-going population will have functional English by 2015 (Adkins, 2014, p. 24). However, in countries where English has already been in use there is still strong demand of special forms English language proficiency; governments have been making efforts in improving the teaching of English language in schools and enhance English language proficiency in other areas. According to Adkins's (2014) report, the EQUIP-T ELT initiative in Tanzania, which runs from 2014 to 2018, is a newly designed method for improving the teaching of English. In the view of the government, "the current global development demands have made the English language a crucial tool for communication in the world, making it necessary for government to find ways to help the young generation master the language." (Adkins 
2014, p.10) In the same report, the British Council is reported to sign a Declaration of Intent (DOI) with the South African Department of Basic Education (DBE) "to improve the country's English as a First Additional Language (EFAL) programming and delivery" (Adkins 2014, p.10).

Accordingly, people need English for several reasons including but not limited to accessing further education which is provided in the medium of English; this is especially the case for education available in the European universities and America (which also demand good passes of international English tests). Furthermore, people need English for career development and professional advancement; they also need English to have a global reach in other transactions including econocultural features such as business, international trade, market competition and other global networking (Brutt-griffler, 2002; Rugemalira, 2005). In recent years, the demand for specialised forms of English (also called vocation English) has taken new levels in areas such as aviation, hospitality, finance, medical, transportation, mining, oil and gas. Increasingly, especially in Africa, people believe that at one point or another in time they will need English to get by in certain domains of life, besides those mentioned above. In the past, it was generally assumed that good language abilities and communication skills were only relevant in the field of education, and thus students in schools and universities were the only people who needed to worry about language competencies and communication skills. Studies (Adkins 2014; British Council, 2006) and experience have shown that there is an ever widening scope where English language and communication skills seem to exert influence in people's everyday lives. In Tanzania, people need English language and communication skills not only in education but also in employment, full participation in social and political discourses, and in Information and Communication Technology (ICT). Also, the role of English cannot be undermined in the domain of entertainment (films, music, comedy, sports and games) which unequivocally claims majority of audience especially in the urban areas (The Tanzania Country Level Knowledge Network [CLKnet], 2012).

In view of this background, studies and experience have shown that while learners have the motivation and innate ability to learn English, and despite a growing need for Tanzanians of all ages to learn English, there is lack of requisite opportunities to learn and practice the language. Even for those learners who have the opportunity to attend English classes; they consistently cannot use the language proficiently despite their motivation to learn and willingness to invest time and money into training. This problem is due to lack of systems especially in Tanzania which could exploit this opportunity and render requisite services in addressing the rising demands. There are many reasons to this problem; to begin with, many English language learning proficiency programs in Tanzania are unstructured and not tailored to learners' particular interests, this is in addition to using methodologies that emphasize on teaching about language instead of teaching language use (Mtitu, 2014). Furthermore there is a significant shortage of English languages teachers who are qualified to run such programms; there is also poor infrastructure, and lack of supportive environment for language use (Ministry of Education and Vocational Training [MoEVT], 2014a). Experience has shown that there is a mushrooming of English proficiency courses which are offered by unprofessional educational establishments. Although universities are endowed with resources and expertise to design professional based courses which could address specific learning needs of English learners, there is little evidence that they have been involved in designing and implementing tailor made courses to such target groups. As a result, such programms fail to develop learners' communicative competencies in their areas of interest. Thus, this problem makes the demand for programs on specialized forms of English language learning and communication skills an area worthy researching.

The current study therefore sought to explore the roles in which universities in Tanzania could play to address the rising market demand of programms on specialized forms of English language learning and communication skills with the aim of providing outreach services and generate revenue.

Specifically, the study sought to answer the following questions; first, what are the areas with high demands in programs of specialized forms of English language learning and communications skills? Secondly, what appropriate actions universities in Tanzania can take to respond to the said market demand? Previous studies (Brock-Utne, Desai \& Qorro, 2003, 2005; Komba, \& John, 2015; Mohamed, 2005 2006, 2008; Qorro, 1999, Rugemalira; 2005;) have mainly focused on problems of language and communication skills in our learning and teaching systems in schools and universities. Little (if any) has been documented with regards to how universities can respond to the rising market demand of specialized forms of English learning language and communication skills, and especially as a niche which universities can use to expand their outreach services and at the same time generate revenue .

Many public universities have been constrained with financial resources due to budget cuts from the government (Devarajana, Mongab, \& Zongo, 2012; Kavuma, 2011, Macuacua, 2008; National Association of State Universities and Land Grant College [NASULGS], 2008). These financial constraints in universities have among other things 
been caused by pressures for expansion and massification, (increasing of students' intake) which is reported to have reached ' ... a critical stage where the lack of resources has led to a severe decline in the quality of instruction and in the capacity to reorient focus and to innovate." (Kavuma, 2011, p.2)

As a result, universities have been findings ways of buffering their cash strapped coffers for recurrent expenditure, and thereby facilitating their smooth operations. According to the British Council (2006) statistics, the provision of English Language (EL) has undoubtedly become a valuable constituent of the economy in countries such as Australia which was estimated to generate as much as AUD \$932 million in 2004; the New Zealand, EL sector was estimated to be valued at over NZD $\$ 400$ million in 2003/4. Africa is reported to have the highest growth rate of English digital product in the world, and whose revenue reached US 19.5 million in 2013. This figure is projected to more than double to US 49.5 in 2018 (Adkins, 2014).

Many studies (Economic and Social Research Foundation [ESRF], 2006; MoEVT, 2015) on assessing human capital in different sectors established a gap between required skills in the labour market and the ones supplied by the education system. For example, "out of 700000 new entrants into the labour force every year about 500000 are school leavers with few marketable skills" (ESRF, 2006. p. 1). According to the MoEVT (2014b) report, $85 \%$ of the working population in Tanzania constitutes low skilled workers. This is a huge gap given that skills are equivalent to deliverance and good performance. Indeed, high skilled labour is an important part of the National Strategy for Growth and Reduction of Poverty, known by its Kiswahili acronym MKUKUTA, as an implementation strategy for realizing one of the Millennium Development Goals.

In another report on assessing human capital in the tourism industry the imbalance between the demand and supply of generic skills is reported to be widespread. The skills gap that cut across all tourism sub-sectors are reported to be notorious in the field of "communication - multi-lingua and interpersonal skills (good organizational, speaking and public relations skills); customer care; marketing and sales skills; innovation and creativity skills; leadership and managerial skills and basic knowledge in ICT" (MoVET, 2015. p.14).

On these grounds the current study is carried out as a pointer which highlights one of the potential areas which universities in Tanzania can exploit in view of not only providing services which meet clients' expectations but also making language departments contribute to revenue generation for university coffers.

\section{Methods}

\subsection{Participants}

The data for this study were collected in Tanzania and two universities in Ghana in 2014 following a qualitative research design. Two universities in Ghana were the University of Cape Coast (UCC) and the University of Ghana (UG). Ghana was preferred because it has many salient features which other African countries did not seem to have. First, Ghana uses English in her education system, but so does Kenya and Uganda. However, Kenya and Uganda are multilingual societies whose linguistic diversities make English a necessary neutral language of communication not only in a classroom but also outside the classroom. In Ghana, however, Twi and Fante, (the dialects of Akan) are the dominant local languages, and they are used in the outside community, as is the case for Kiswahili for Tanzania. Therefore, Tanzania has more in common with Ghana linguistically than with both Kenya and Uganda. The UCC and the UG were chosen because of the presence and innovativeness of English-language teaching programs and resource centres, experience in implementing Communicative Language Teaching methodologies, the use of ICT and e-learning in fostering language teaching and learning, and lastly the implementation of tailor made courses to particular groups of learners with special language needs. As for the identification of areas on special language needs in Tanzania, a market survey was conducted in 2014.

In Tanzania, a total of 12 organizations were purposefully selected and used in this exercise, namely banking sector, education, hospitality industry, business, construction, NGOs, law enforcement and security, administration, engineering, and agriculture. The inclusion of these organisations depended on the services (which involved interface between provider and customer). In the organisations, managers and employees were involved while in the education sector teachers, administrators, and university graduates were included in the study.

\subsection{Sampling Procedure}

\subsubsection{Ethical Considerations}

This study followed standard procedures for social research, whereby permission was sought from relevant institutions and granted. The study survey in Ghana was carried after the universities were informed of the objectives 
of the intended study. The market survey in Tanzania was done after the consultation and presentation of the objectives of the study to the identified organisations. All participants in the study willingly agreed to participate and confidentiality of the participants was strictly observed.

\subsubsection{Sampling Techniques}

A total of 108 employees (employee include also managers) and 105 university students and graduates were selected. Purposive sampling was used to select employees in the study from the selected organisations, mainly depending on the nature of the sections involved. University students and graduates were randomly selected using snow bowling technique. In universities, participants in the study included administrators and instructors from language departments and centres. Three administrators and fifteen members of academic staff were purposely selected from each of the two universities in Ghana.

\subsubsection{Instruments}

Several tools were used to collect data and these include face to face and telephone interviews, focus group discussion, and questionnaires. Face to face and telephone interviews were mainly administered to managers because these seem to have in depth insights regarding areas of special language needs in their organisations. Questionnaires were administered to university graduates and other employees (except managers) in the market survey in Tanzania. Secondary sources from online and offline stored data on human resource needs and challenges on university funding in Africa were used to enhance or validate the findings from the survey. Face to face interviews were done to the administrative staff from the Language Centre of the University of Ghana and the Department of English and the Department of Communication Skills from the University of Cape Coast to inquire information on areas, clientele, and the conduct of courses on language for special purposes. Similar interviews as well as focus group discussion were conducted to instructors to explore issues on course structure and implementation strategies of their English language courses. Documentary review was employed to gather information regarding teaching the course and teaching and learning materials in use.

\subsubsection{Study Design and Data Analysis Method}

This study followed a survey research design where data were collected from a sample of respondents from a defined population as explained above. Data were analyzed using qualitative and quantitative data analysis methods. For qualitative data thematic analysis approach was used, while for the quantitative data SPSS and excel were used. The findings were presented to address specific research questions.

\section{The Findings and Discussion}

\subsection{Areas with High Demands in English Language Proficiency Programmes and Communications Skills}

In this aspect, data were collected from university students and graduates and employees. When asked to indicate areas where they mostly use English 43.4 percent of university graduates indicated to use English for reading various materials such as books, magazine and newspapers, 22.9 percent, mainly use English for watching television and 23.8 percent use it for class works (such as assignments and presentations). There are few respondents who use English for speaking and internet surfing representing 5.7 percent and 3.8 percent of the respondents respectively. The numbers for those who use English in speaking is very small because it is one of the areas that the respondents reported to be their weakest point and needed improvement

When asked to indicate areas where they mostly need to use English in their workplace, 74.1 percent of employee reported to need English primarily to communicate with their clients; 19.4 percent need it for report writing and work related materials, 5.6 percent need it for communicating with other employees, while only 0.93 percent need it for meetings. However, as indicated in Table 1, speaking is leading among the skills which respondents reported to be linguistically challenged. This is followed by listening, writhing and lastly reading. This indicates that the leading English language learning demand is in the area of spoken communication, listening, and writing (reports or other related work materials). These findings concur with the rationale of designing a Diploma Course in English Language Teaching in Tanzania in 2009, and whose syllabus states categorically that "English Language has become a tool of communication to facilitate both national and international interactions in business, science and technology, education, foreign relations as well as others areas" (MoVET, 2009, P. v). 
Table 1. The Challenges Faced By Employee in Using English

\begin{tabular}{lll}
\hline Challenge & Frequency & Percentage \\
\hline Speaking & 66 & 61 \\
Writing & 12 & 11.1 \\
Reading & 10 & 9.3 \\
Listening & 20 & 18.5 \\
TOTAL & 108 & 100 \\
\hline
\end{tabular}

\section{Source: Research Data 2014}

These are the areas where universities could exploit in designing English language proficiency learning programms accordingly.

\subsection{Marketability of the English Language Proficiency Programms}

In this aspect, the study intended to find out the marketability of English language proficiency programs in these areas (speaking, writing, reading and listening). Majority (see Table 2) of university students and graduates interviewed indicated willingness to join; this is followed by those who are ready to join the course, provided the fee was affordable. And a small percentage said that they were willing to join, but it would be dependent on payment conditions. Others were of the opinion that they were willing to learn, provided time allows (whether the course would be flexibility). Some pointed out that the course was important, but they were not sure if they would join, and a very small percentage of respondents were not willing to join the course.

Table 2. University students and Graduates' Willingness in Attending English Proficiency Programmes

\begin{tabular}{lll}
\hline Willingness & FREQUENCY & PERCENTAGE \\
\hline Willing to attend the programmes & 65 & 61.9 \\
Willing to attend, depending on the fee structure & 32 & 30.47 \\
Willing to attend, depending on delivery time. & 4 & 3.8 \\
Willing to attend but not this year & 3 & 2.9 \\
Not willing to attend & 1 & 0.95 \\
Total & 105 & 100 \\
\hline
\end{tabular}

Source: research data 2014

Table 3. Employees' Willingness in Attending English Proficiency Programme

\begin{tabular}{lll}
\hline Willingness & Frequency & Percentage \\
\hline Willing to attend the programme & 38 & $35 \%$ \\
Willing to attend, depending on the course structure & 54 & $49.93 \%$ \\
Willing to attend, depending on delivery time & 9 & $8.3 \%$ \\
Willing to attend, depending on the fee structure & 7 & $2.7 \%$ \\
Total & 108 & 100 \\
\hline
\end{tabular}

\section{Source: Research data 2014}

The findings on the marketability of the programme for employees indicate that a good number of workers (See Table 3) were willing to attend the programme; a substantive percentage indicated to be willing to attend, depending on the course structure, a small percentage indicated willingness to attend, depending on delivery time, and a few others reported to be willing to attend the programme depending on the fee structure; and there was no one who said he/she would not be willing to attend the programme.

On the whole, the findings indicate that research participants had favourable and positive views about the course. A significant number of them indicated that they were willing to join the course and suggested that the course be practical oriented. There was also a significant number who had a concern with payment (especially among university students) and a small number who had a concern with time (especially among employees),

Interestingly, the findings show that only a very small percent $(2.7 \%)$ of employees reported that attending the programme will depend on the fee structure. On the other hand, a significant number ( 30.47 percent) of university 
students and graduates reported that attending the programme will depend on the fee structure. This implies that financial resource for employees is not a constraint in attending the programme; which indicates availability of stable market for the programme.

Similarly, the assessment of motivation and expectation indicates that availability of professional teachers and practical sessions, fair fee, and learners' passion for understanding the language were key drivers behind attending the programme. This implies therefore that the course design should take into account the practical sessions and professionalism. The area of passion towards understanding the course also implies that employees believe they need English for full participation in social and other discourses apart from employment.

As it can be seen, there were overwhelming concerns over professionalism on the course delivery, which is to do with the teaching staff. This is understandable, as pointed out earlier; many potential learners are frustrated by lack of requisite expertise with many English courses which have mushroomed especially in urban areas in Tanzania for purely financial gains. Such courses have often been unstructured, with no specific learning outcomes and offered by people with questionable qualifications (Mtitu, 2014). This is the area where universities can exploit because these are institutions endowed with the resources and expertise to design professional based courses which address specific learning needs.

\subsection{Experiences of Delivery of English Language Proficiency Programmes in Universalities in Ghana}

The Language Centre at the University of Ghana which started in 1970 is primarily a research and teaching centre. Apart from academic writing course (which is equivalent to Communication Skills course offered at universities in Tanzania) and which is offered as a compulsory course to regular university students, the Language Centre also offers English proficiency programmes. These programmes offer services to university students from francophone Africa who come to the University of Ghana, as most of these have no English language background. The programmes basically focus on four language skills which are reading, listening, writing and speaking plus English literature. Within the Proficiency programmes there are also

i. courses on demand- which can be individual or personalized courses

ii. Special English courses offered on request: Companies bring students for tailor training for specific needs especially on speaking skills; at the time of data collection for this research the Centre was running

a. English for AngloGold Ashanti employees

b. English for Samsung employees

iii. group courses- for example at the time of data collection for this research the Centre had admitted up to 290 students from Burkina Faso to take 2-3 years immersion programmes.

iv. English for Specific Purposes (ESP) courses for example, English for PhD students, English for agriculture, and English for Law are often requested by other departments for its students in place of the general academic requirement.

Although the UG finances teaching and learning materials through University Bookshop or the Library, clients pay for the courses including teaching materials, and academic facilities user fee. Programme fee ranges from $\$ 2000$ and $\$ 3000$. On average, the Language Centre generates up to $\$ 200000$ per year, all of which goes to the central University financial pool. All staff are entitled to a regular salary, and extra teaching (especially in the proficiency programme). The university takes 35 percent of the income for use on the facilities and 15 percent goes to the Centre. The remaining 50 percent of the fees goes to the instructor. For specific courses requested by departments, instructors are directly paid by the departments. It was also reported that the Language Centre was then one of the largest contributor to University revenue collection.

At the University of Cape Coast, Two (2) Departments were found dealing with English language, namely the Department of English and the Department of Communication Skills which was formally under the Department of African languages and Development Studies. This Department became fully fledged Department of Communication Skills whose mandate is to provide academic literacy skills to students across University faculties.

All students across faculties at the University take Communication Skills (CS) as a mandatory course in 2 semesters. Lessons are offered to students in clustered groups irrespective of their disciplines of specialization due to logistical difficulties of designing and offering discipline specific CS courses. It is the same arrangement found at universities in Tanzania. 
On the other hand, apart from running English regular programmes especially in General Linguistics, the Department of English at the UCC also runs programmes in English as a Foreign Language. At the time of data collection for this research, all the faculties at the University were supposed to be generating their own income. The University has rules and regulations for managing the funds. In view of this, the Department of English also designed English language proficiency courses. Accordingly, the Department was offering

I. English for Foreign Learners (EFL); this is one year programme offered to foreign university graduates from non English speaking countries particularly Bo kina Faso and Ivory Coast. The course focuses on all the four language skills and English grammar.

II. English For special Purposes (ESP); this is a six -week to three month course aimed at helping professionals to improve their English skills. The clients come from different organizations. There is ESP for teachers and language practitioners -which can go up to $\mathrm{PhD}$ level. The goal is to train learners acquire knowledge in the use of English in professional settings, and prepare learners to become language professionals.

Short course Programmes are run during long vacations and so staff can decide to stay and teach these courses. Organizations contact the Department directly for the running costs of the programmes. Staffs involved in the teaching of the programmes are from the two Departments; tutorial assistance ship is also rendered by research university graduates in MPhL, Masters, and $\mathrm{PhD}$ programmes.

At the time of the research, the University was constructing a large multi-purpose language centre which is intended to serve a number of language departments. The building is designed to accommodate large and small language laboratories; a film editing facility (which can be an income generating and an open area for student study and offices for staff). The French Embassy was planning to move into the new laboratory for rendering services on French language. The Chinese Embassy was also expected to participate in rendering services in Chinese. It was reported further that some of the laboratories would have computers with software that were meant for helping in teaching and learning languages. Other laboratories were expected to be equipped with Customized Language Technology like booths that communicate with the main console of the instructor. The Ghana Education Trust Fund was building the Facility, and the Bank of Ghana later took over and had donated funds for the building as part of their social development initiative.

\section{Conclusion and Implications for Universities in Tanzania}

Universities from Tanzania have a lot to learn from the findings of the study. Firstly, because a study on special language needs in Tanzania has shown that English language proficiency is a potential niche market which Tanzanian universities could exploit to meet the rising language demands and at the same time generate the much required income.

From a study survey in Tanzania, universities can use several tools to market the programmes; a market communication mix, can be used whereby mass marketing and personal marketing become a communication tool for the programme. For personnel communication, tracks can be sent out to various organizations for awareness. Mass marketing can also involve television, radio, and newspapers. This will enable to reach many participants at once. Interview sessions can be conducted using the local television and radio stations. The focus of programmes delivery should be on quality dimensions such as environment, teachers, the teaching process, as well as meeting specific learning needs of clients. In this respect, the universities should be flexible to design courses that meet specific learning needs of clients.

It was further observed that a driver for proficiency courses is customer care service; because this is what guarantees business continuity and referrals. Also, flexibility and customization of courses were cited as crucial. This is a useful lesson for universities in Tanzania which could exploit opportunities in the ever expanding information and communication technology industry which need workforce with special competencies in English language proficiency. There is also the newly emerging sector of oil, and gas whose successful performance will depend on the availability of skilled labour with competence in the medium of English.

As it we have seen in the studies cited above (see. ESRF, 2006; MoEVT (2014b; MoEVT, 2015), which assessed human capital in different sectors established a gap between required skills in the labour market and the ones supplied by the education system. Accordingly, the area of communication - multi-lingua and interpersonal skills (good organizational, speaking and public relations skills) has been cited as the most challenging in the skills gap reports. In this respect, universities have a huge responsibility of filling this skills gap and one of such skills gape is undoubtedly English language proficiency and Communication Skills. 
As surveys and literature have indicated, the demand for specialized forms of English language learning and communication skills is strong. In order to help language departments render these services to clients within and outside universities, initial investment in language teaching and learning by Tanzanian universities is inevitable. The universities need to create an environment such that language departments can be able to freely generate and manage their own finances but at the time contributing to university coffers

Partnerships between public and private sectors are highly needed to facilitate establishment of such programmes. We have seen that at the University of Cape Coast, the government has invited sponsorship from the banking sector and embassies to finance the construction of large multi-purpose language centre. This would not have been possible without the University and or government support. This is especially more important in situations like Tanzania where donors investment in the service sector such as educations is not paramount and where it happens then disciplines in humanities (e.g. languages) get least attention in such investments.

\section{Acknowledgements}

We highly acknowledge Innovative Agricultural Research Initiative (iGRAI- SUA) for the financial support which helped the researchers to travel to Ghana. We also acknowledge Sokoine University of Agriculture (SUA) for granting permission to researchers to travel to Ghana for data collection. We extend our gratitude to the Language Centre University of and Department of English and Department of Communication Skills of the University of Cape Cost for agreed to participate in the study. Lastly, we owe many thanks to all organisations and individuals who willingly provided with highly valuable information.

\section{References}

Adkins, S. S. (2014). Ambient Insight Regional Report: The 2013-2018 World Digital English Language Learning Market; New Government Policies Increase Revenue Opportunities for Suppliers. Retrieved from http://www.ambientinsight.com

British Council (2006). A review of the global market for English language courses. Retrieved from http://www.eduactionuk.org/eumd-information-research.htm

Brock-Utne, B., Desai, Z. \& Qorro, M. (eds.) (2003). Language of Instruction in Tanzania and South Africa. Dar-es-Salaam: E\&D.

Brock-Utne, B., Desai, Z. \& Qorro, M. (eds.) (2005). Language of Instruction in Tanzania and South Africa. Dar-es-Salaam: E\&D.

Brutt-griffler, J. (2002). World English: A study of its development. Celevedon: Multilngula Matters Press.

Devarajana, S., Mongab, C., \& Zongo, T. (2012). Making Higher Education Finance Work for Africa. Journal of African Economies, 20, 133-154.

Economic and Social Research Foundation. (2006). Policy Dialogue Seminar Paper on Opportunities and Challenges for Rural SMEs Development in Tanzania. Retrieved from http://www.tzonline.org/pdf/policydialogueseminarpaperonopportunitiesandchallenges.pdf

Kavuma, R.M. (2011, September, 9). In Africa's Universities, quantity threatens quality. The Guardian, p2. Retrieved

From http://www.theguardian.com/global-development/poverty-matters/2011/sep/09/africa-university-funding-crisis

Komba, S., \& John, D. (2015). Investigating Pupils 'Ability in Tanzania, The case of English Medium Primary Schools. World Journal of English Language, 5(1), 56-64. http://dx.doi.org/10.5430/wjel.v5n1p56

Macuacua, A. (2008). The Funding Challenge for The African Universities. Personal Collection of A. Macuacua. Eduardo Mondlane University, Maputo, Retrieved from https://www.google.com/url?sa=t\&rct=j\&q=\&esrc=s\&source=web\&cd=2\&cad=rja\&uact=8\&ved=0ahUKEwjy zcXq6b_LAhWE1BoKHWcND60QFgg0MAE\&url=http\%3A\%2F\%2Fwww.coimbra-group.eu\%2Faudis\%2Fd ocs\%2F03_0406\%2520Macuacua\%2520Challenges\%2520of\%2520Funding\%2520African\%2520Univ\%2520E ng.ppt\&usg=AFQjCNEuappUjsxUN3KFdDKuI4x0ObUDBQ

Ministry of Education and Vocational Training. (2009). English Pedagogy Syllabus for Diploma in Secondary Education. MOEVT, Dar es Salaam. 
Ministry of Education and Vocational Training. (2014a). Education and Training policy. MOEVT, Dar es Salaam.

Ministry of Education and Vocational Training. (2014b). Consultancy Study on Human Resource Needs and Skills Development of the Agribusiness Subsector in Tanzania. MOEVT, Dar es Salaam.

Ministry of Education and Vocational Training. (2015). Human Resource Needs and Skill Gaps in the Tourism and Hospitality Sector in Tanzania. MOEVT, Dar es Salaam.

Mohamed, H. I. (2005). Critical Issues on the Language of Instruction (LOI) in Secondary and Higher Education in Tanzania. Uongozi Journal of Management Development Dynamics, 17(1), 32-51. http://dx.doi.org/10.2167/jmmd548.0

Mohamed, H. I., \& Banda, F. (2008). Classroom Discourse and Discursive Practices in Higher Education inTanzania. Multilingual and Multicultural Developments, 29(2), 95-109.

Mohamed, H.I. (2006). Academic writing as social practice: A Critical Discourse Analysis of Student Writing in Higher Education in Tanzania. Unpublished PhD Thesis. University of the Western Cape, Republic of South Africa.

Mtitu, E. A. (2014). Learner-Centred Teaching In Tanzania: Geography Teachers' Perceptions And Experiences. Unpulished $\mathrm{PhD}$ Thesis. Victoria University of Wellington. Retrieved from http://researcharchive.vuw.ac.nz/xmlui/bitstream/handle/10063/3226/thesis.pdf? sequence=2

National Association of State Universities and Land Grant College, (2008). Challenges of Higher education in Africa and lessons of Experience for the Africa - U.S. Higher Education Collaboration Initiative. Washington D.C. Yizengaw, T. Retrieved from http://www.international.ac.uk/media/4075/challegnes\%20in\%20africa.pdf

Qorro, M. (1999). A Qualitative Study on the Teaching and Learning of Writing in English in Tanzania Secondary Schools in Relation to the Writing Requirements of Tertiary Education. Unpublished Doctoral thesis. Dar es Salaam: University of Dar es Salaam.

Rugemalira, J.M. (1990). The Communication Skills Unit and the Language Problem at the University of Dar es Salaam. In Casmir M. Rubagumya (ed.), Language in education in Africa: A Tanzanian Perspective. Clevedon: Multilingual Matters, pp. 105-122.

Rugemalira, J.M. (2005). Theoretical and practical challenges in a Tanzanian English medium primary school. Africa \& Asia Journal, 5, 66-84.

The Tanzania Country Level Knowledge Network. (2012). Audience Forum Report No 5: Addressing Employment Challenges in Tanzania: Strategic Policy Options and Actions by Stakeholders. Retrieved from http://www.clknet.or.tz/wp-content/uploads/2013/01/CLKnet-Forum-5-Report-Employment-Challenges.pdf 